

Zoological Institute, Russian Academy of Sciences, St Petersburg • https://www.zin.ru/journals/zsr/

Vol. 28(1): 3-18 - Published online 7 March $2019 \cdot$ DOI 10.31610/zsr/2019.28.1.3

RESEARCH ARTICLE

\title{
An instance of intergeneric copulation in the family Rhopalidae (Heteroptera): structure, functioning and congruence of the genitalia in two different species from the standpoint of the lock-and-key hypothesis \\ Случай межродового спаривания в семействе Rhopalidae (Heteroptera): структура, функционирование и конгруэнтность гениталий двух разных видов с точки зрения гипотезы «ключ-замок»
}

\author{
D.A. Gapon
}

Д.А. Гапон

Dmitry A. Gapon, Zoological Institute, Russian Academy of Sciences, 1 Universitetskaya Emb., St Petersburg 199034, Russia. E-mail:tentatdag@gmail.com

\begin{abstract}
An event of mating between specimens of Corizus hyoscyami and Rhopalus parumpunctatus, registered in the Novgorod Province of Russia is considered. The structure of the aedeagi in their completely inflated state and the female genitalia, as well as the functioning of the genitalia, are described and illustrated. The process of unfolding and swelling of the aedeagi is traced using the method of hydraulic inflation of the membranous parts with glass microcapillaries. The congruence of the genitalia is discussed for each species, and also for the interspecific crosses in both combinations of sexes and species. Structures of insect terminalia are divided into three groups according to their functions: 1) auxiliary structures; 2) structures providing the mutual fixation of the genitalia; and 3) structures directly performing the function of transferring seminal fluid. It is shown that in the considered variants of interspecific crosses, the parts of the genitalia belonging to the second group have almost the same structure and functioning, and most likely cannot perform the function of structural isolation. The structures of the third group have taxon-specific morphological and functioning traits and a high degree of congruence within each species. Schemes of the functioning of the genitalia in interspecific crosses, speculatively showing the impossibility of normal insemination, are proposed.
\end{abstract}

Резюме. Рассмотрен случай спаривания между Corizus hyoscyami и Rhopalus parumpunctatus, зарегистрированный в Новгородской области России. Описано и проиллюстрировано строение эдеагусов в полностью раздутом состоянии и гениталий самок, а также их функционирование. Прослежен процесс расправления и раздувания эдеагусов при помощи метода гидравлического их раздувания с использованием стеклянных микрокапилляров. Рассмотрена конгруэнтность гениталий для каждого вида, а также в межвидовых скрещиваниях в обеих комбинациях полов и видов. Структуры терминалий разделены на три группы по их функциям: 1) вспомогательные структуры; 2) структуры, обеспечивающие взаимную фиксацию гениталий; и 3) структуры, выполняющие функцию передачи семенной жидкости. Показано, что структуры второй группы в рассматриваемых вариантах межвидового спаривания имеют почти одинаковое строение и, скорее всего не могут выполнять функцию структурной изоляции. Структуры третьей группы имеют специфическоедля каждого таксонастроениеи особенности функционирования, обладая высокой степенью конгруэнтности внутри каждого вида. Предложены схемы функционирования гениталий в межвидовых спариваниях, умозрительно показывающие невозможность нормального осеменения. 
Key words: genitalia, aedeagus, gynatrium, functioning, congruence, structural reproductive isolation, lock-and-key hypothesis, insects, Heteroptera, Rhopalidae

Ключевые слова: гениталии, эдеагус, гинатриум, функционирование, конгруэнтность, структурная репродуктивная изоляция, гипотеза «ключ-замок», насекомые, полужесткокрылые, Rhopalidae

ZooBank Article LSID: urn:lsid:zoobank.org:pub:6C796633-E732-4F3C-8114-D123D5073588

\section{Introduction}

The lock-and-key hypothesis has been proposed by Dufour in 1844 in an extravagant statement, 'L'armure copulatrice est un organe ou mieux un instrument ingénieusement compliqué, destiné à s'adapter aux parties sexuelles externes de la femelle pour l'accomplissement de l'acte copulatif; elle est la garantie de la conservation des types, la sauvegarde de la légitimité de l'espèce'. Since then, quite a lot of data has been accumulated for different groups of animals, both confirming and disproving this hypothesis; review of these data is given, for example, by Mayr, 1963; Shapiro \& Porter, 1989; and Masly, 2012 (I deliberately shy away from the consideration of particular examples and theoretical considerations proposed in the literature, since otherwise the volume of the article would have increased by several times). It seems more correct to designate this concept not as a hypothesis, but as the lock-and-key rule or Dufour's rule, which can be formulated as follows: complex structured genitalia of various animal species are congruent in the sexes inside the species and operate like a key and lock, preventing hybridisation between individuals of different species. The challenge for researchers is to test the applicability of this rule to as many taxonomic groups as possible, taking into account past methodological errors, when only the external and auxiliary, not participating in closest contact parts of genitalia were involved in the analysis (for more on this, see below in the Preliminary reasoning section). One of model objects convenient for particular testing of the lock-and-key rule is considered in this article.

Some time ago I have received photos of copulating true bugs (Fig. 1; Figs 13-15 as electronic supplementary material) which were identified by me as Corizus hyoscyami (Linnaeus, 1758) and Rhopalus parumpunctatus Schilling,
1829. According to the author of the photos, E.Yu. Kirtsideli, the mating was lasting during about 20 minutes while photographing and was continued thereafter, although no further observations were carried out and the material was not collected. This event of intergeneric copulation is curious per se and interesting from the standpoint of the lock-and-key rule. Obviously, the reproductive isolation mechanism of genitalia did not operate in this case, since the copulation began and lasted for rather a long time (unfortunately, it is not known how long it lasted as a whole and how long the normal copulation continues for each of these species). Therefore, it seems to me interesting to consider the structure of the genitalia in these species for understanding why copulation between these rather strongly diverged species from the group having a complex structured aedeagus turned out to be possible; and whether the mechanism of structural isolation which is supposed to prevent insemination was implemented.

Thus, the purpose of this work was to examine the structure of male and female internal ectodermal genitalia in $C$. hyoscyami and $R h$. parumpunctatus, the functional morphology of these structures and to evaluate a degree of their morphological and functional congruence in the interspecific cross, both direct and reciprocal.

\section{Material and methods}

The photographs of mating true bugs were taken on 29 May 2013 in a meadow near Terekhovo Village, Novgorod Province, Russia. The genitalia of dry specimens of $C$. hyoscyami and $R h$. parumpunctatus were examined basing on the material from collection of the Zoological Institute, Russian Academy of Sciences. The structure and functional morphology of the aedeagi was studied by the method of hydraulic inflation using glass 


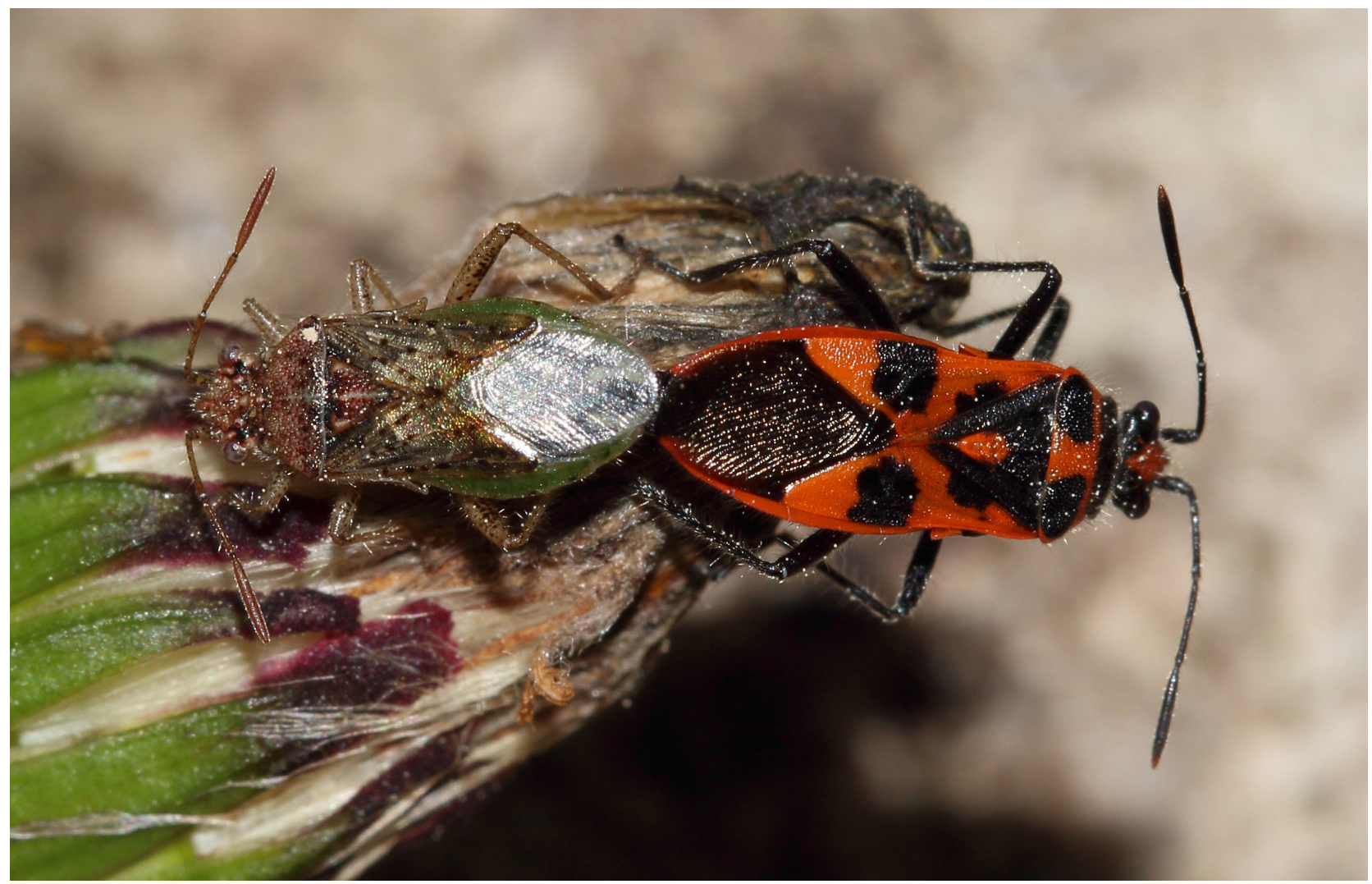

Fig. 1. Copulation of Corizus hyoscyami (male) and Rhopalus parumpunctatus (female), Novgorod Province. Photograph by E.Yu. Kirtsideli.

microcapillaries (Gapon, 2001). Female terminalia were anatomised by the standard method after boiling for 2-3 minutes in $15-20 \% \mathrm{KOH}$ solution; when necessary, gynatrial membranes were stained with methylene blue. In all cases, including consideration of the functional morphology, the aedeagi are described according to their position in an inverted pygophore, i.e. in copula. Thus, the right side of the aedeagus in the descriptions corresponds to the left side of the gynatrium. Terminology for parts of the endosoma is based on the topographic principle and follows Konstantinov \& Gapon (2005) and Gapon (2007); terminology for parts of the internal ectodermal genitalia of females follows Štys (1961) and Gapon (2007).

\section{Structure of the genitalia}

\section{Corizus hyoscyami (Linnaeus, 1758)}

(Figs 1-6, 10, 11; Figs 13-16 as electronic supplementary material)

Material examined. Ukraine: Volyn Prov., Lokachi Distr., Markovichi Settlm., 11.V1899, 4 males,
1 female. Russia: Ryazan' Rrov., Miloslavskiy Distr., Gremyachka Settlm., 13, 27.V.1908 (A. \& Z. Semenov), 1 male, 1 female; Nizhniy Novgorod Prov., Arzamas Distr., Staraya Pustyn', 12,16,22.VIII.1939 (Kiritshenko), 2 males, 3 females; Samara Rrov., Kinel' Distr., Kinel', 23-24,26.VII.1927 (Lubischew), 1 male, 1 female; Volgograd Prov., Sarepta [Volgograd], 30.V.1926 (Obolenskiy), 1 male; Irkutsk Rrov., Tayshet Distr., Yurty Settlm., 23.V1912 (Mishin \& Verkhovsk. [iy]), 1 male. Kyrgyzstan, 1928, 1 male (collector unknown).

Rhopalus parumpunctatus Schilling, 1829

(Figs 1, 7-9, 12; Figs 13-16 as electronic supplementary material)

Material examined. Russia: Tver' Prov.[?], Meledikha Settlm., 16.VII.1912 (S. Rodionoff), 1 female; Moscow Prov., Zaraysk Distr., Gremyachevo Settlm. (L. Bianki), 1 female; Ryazan' Prov., Ryazan' Distr., Sten'kino Settlm., 14.VII.1913 (L. Bianki), 1 male; Nizhniy Novgorod Prov., Arzamas Distr., Staraya Pustyn', 11.VIII.1939 (Kiritshenko), 1 male, 1 female; Voronezh Rrov.: Voronezh env., 9.VIII.1929 (I. Gudim), 1 male; Kalacheevskiy Distr., Kalach, 24-25. 


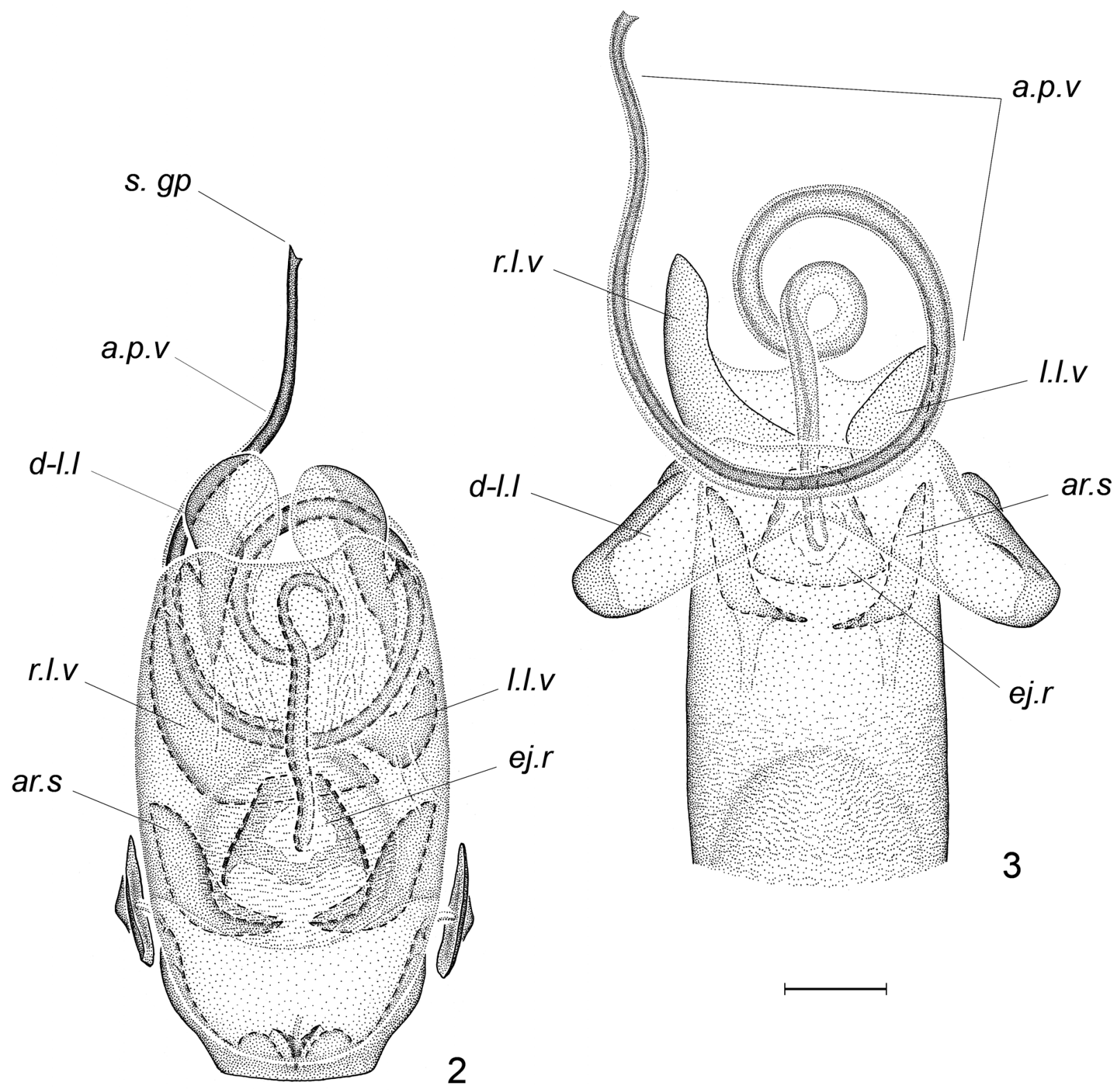

Figs 2, 3. Aedeagus of Rhopalus parumpunctatus. 2, at rest; 3, at very beginning of inflation. Wet preparations in dorsal view. a.p.v, apical part of vesica; ar.s, articular sclerite; $d$-l.l. dorso-lateral lobes of conjunctiva; ej.r, ejaculatory reservoir; l.l.v, left lobe of basal part of vesica; r.l.v, right lobe of basal part of vesica; s.gp, secondary gonopore. Scale bar: $0.14 \mathrm{~mm}$.

VII.1937 (Lukjanovitsh), 1 male; Ternovska Distr., Saval'skoe lesnichestvo [forestry], 3,25.V.1954 (Stark), 1 male, 1 female; "Kubanskaya Prov., Maykopskiy okrug, Mogilki”, 9.VII.1911 (Bogdanov-Katjkov), 1 female; Krasnoyarsk Terr., Kuragino Distr., Mazharka [Settlm.], 19.VI.1925 (Serebrennikov), 2 males; Irkutsk Prov., Irkutsk, 9.VI.1912 (S. Rodionoff), 1 female.

Aedeagus. Phallobase (Figs 2, 7) with relatively narrow basal plates and short arms forming small acute-angled protrusion at posterior-dorsal margin, connected with rather short dorsal connectives. Capitate processes rather small, oval, with very short stalk. In medial part of phallobase, anterio-dorsal margin of its basal plates with two contiguous, rather large triangular protrusions with rounded apices and medial to them with two narrow sclerotised processes splitting at apex and connected with anterior ends of hyaline bands. Transversal bridge wide and short. Ventral 

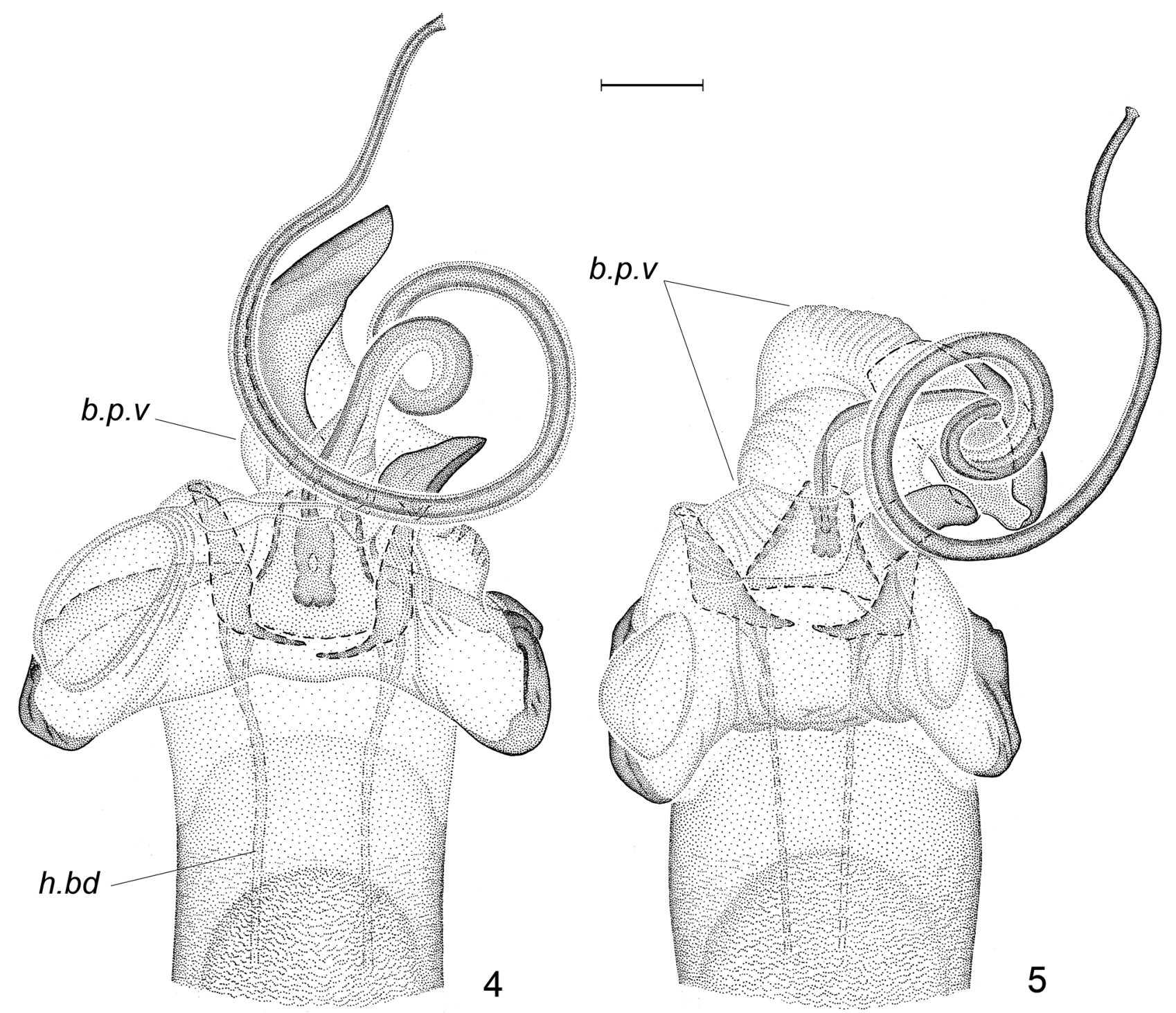

Figs 4, 5. Aedeagus of Rhopalus parumpunctatus in intermediate stages of inflation.4, earlier stage of inflation; $\mathbf{5}$, somewhat later stage of inflation. Wet preparations in dorsal view. b.p.v., basal part of vesica; $h . b d$, hyaline band. Scale bar: $0.14 \mathrm{~mm}$.

(anterior) processes of phallobase not developed, and ventral connectives joining directly to margin of basal plates. Pump of erection fluid rather small, membranous, rounded sac.

Theca (Figs 2, 6-9) uniformly cylindrical, relatively short and wide, about 1.3 times as long as wide. Walls of theca as a whole weakly sclerotised; large part of dorsal wall in its basal half convex, rounded at distal margin, more strongly sclerotised and covered with sculpture of smallest transverse ridges; ventral wall with two wide and somewhat more sclerotised areas percurrent almost from base of theca but not reaching its apical margin, with rounded distal ends. Extreme base of theca membranous at its dorsal and lateral sides, forming rounded, large but weakly convex lateral tubercles at sides, and capable of being swelled. 


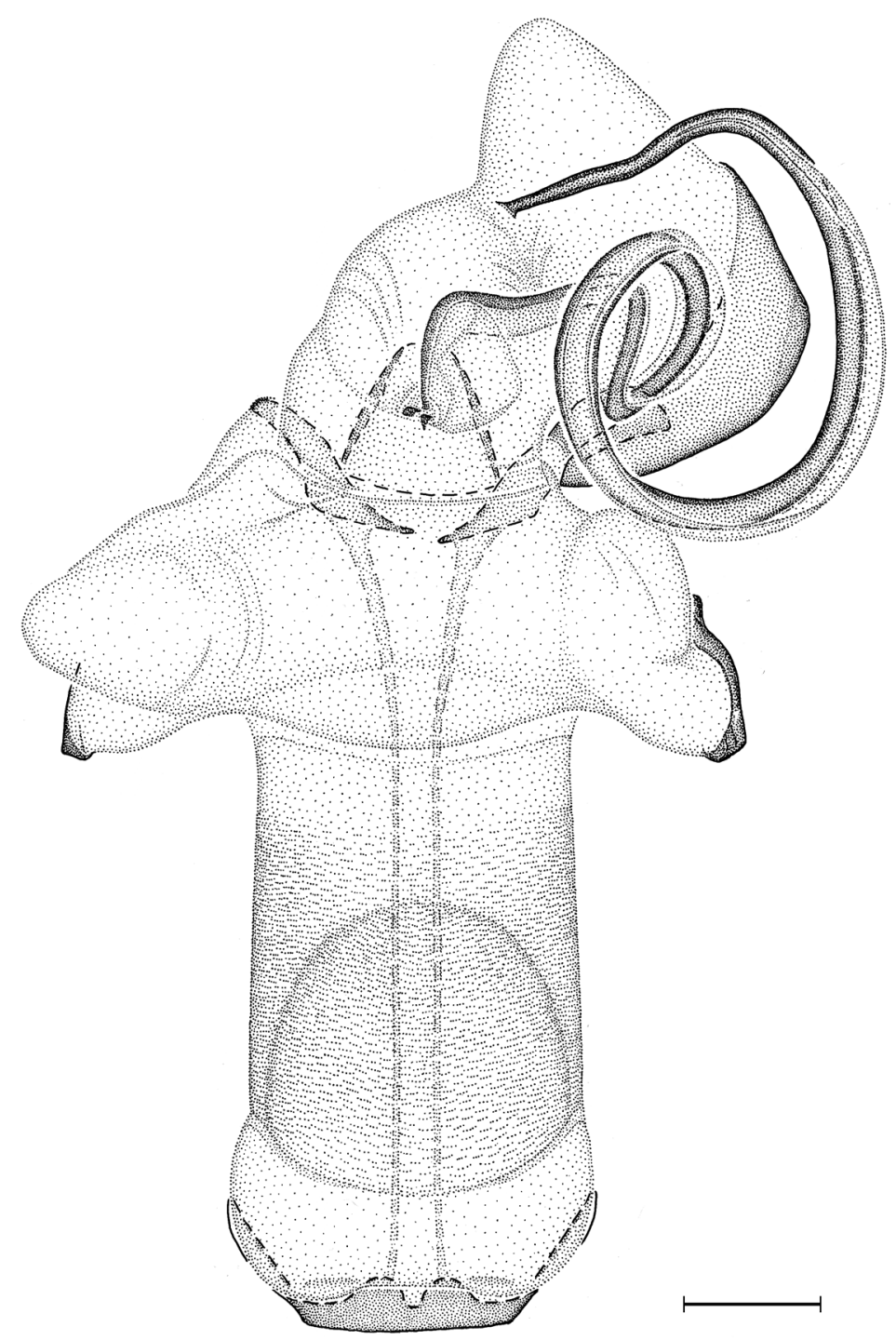

Fig. 6. Completely inflated aedeagus of Rhopalus parumpunctatus. Dry preparation in dorsal view. Scale bar: $0.14 \mathrm{~mm}$.

Conjunctiva (Figs 6, 9) rather short, having convex dorsal wall and bearing a pair of large membranous dorso-lateral lobes. Each lobe with cone-shaped apex, membranous tubercle on posterior wall and elongated sclerite on posteriorventral wall; sclerite reaching apex of lobe and protruding by its ventral margin beyond wall of lobe as sharp ridge; proximal end of sclerite connecting with prominent small conical and sclerotised tubercle. Membranous tubercles on posterior walls of lobes asymmetrical: left tubercle smoother. Both tubercles in Rh. parumpunctatus slightly longer than those in C. hyoscyami, and right tubercle is directed dorso-laterally, while left tubercle is directed posteriad (Fig. 6). In C. hyoscyami, apex of each lobe at inner side with large rectangular membranous protrusion (Fig 9); lobes in $R h$. parumpunctatus smooth at inner sides.

Ejaculatory reservoir (Figs 2-9) in its posterior part weakly sclerotised and having shape of rather large, flattened dorso-ventrally cone with truncated apex directed posteriad. Anteriorventral margin of this cone continued as wide, thickened and strongly sclerotised plate curved at ventral side. Anterior wall of reservoir is represented by two wide and convex sclerotised plates. These plates movably connecting with anterior lateral angles of reservoir and with lateral part of its deflexed ventral plate, and also connecting to each other and to dorsal and ventral posterior margins of reservoir through membrane. Outer parts of these plates continuing into long rod-shaped articular sclerites slightly curving ventrally and diverging by their apices. Wall of endosome intergrowing with posterior margins and apices of articular sclerites and also with both anterior dorsal and deflexed ventral margins of ejaculatory reservoir along their entire length; line of this intergrowth separating conjunctiva and vesica. Posterior ends of two narrow hyaline bands connecting to anterior ventral deflexed margin of reservoir at some distance from each other. Dorsal wall of reservoir near posterior margin with rounded, weakly sclerotised area having in middle narrow, highly sclerotised strip, which splitting and reinforcing place where ductus seminis attaching to ejaculatory reservoir. Ductus ejaculatorius originating from posterior wall of reservoir.

Vesica (Figs 6, 9) consisting of two parts strongly differing in their structure. Basal part of vesica as more or less large membranous sac curved to the left. Right wall of basal part of vesica distal to its base forming large navicular lobe with pointed apex, convex sclerotised outer 




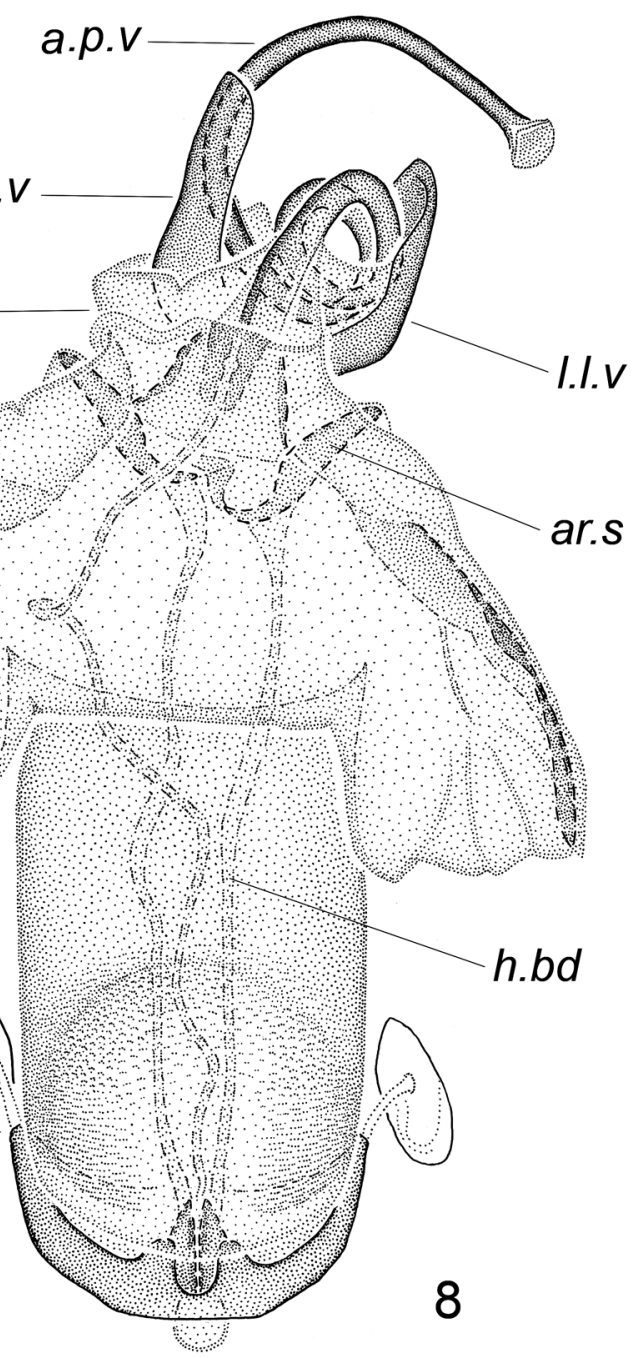

Figs 7-9. Aedeagus of Corizus hyoscyami, sequential stages of inflation. 7 , most initial stage; $\mathbf{8}$, intermediate stage; $\mathbf{9}$, final stage of complete inflation. Wet $(7,8)$ and dry $(9)$ preparations in ventral (7) and dorsal $(8,9)$ views. a.p. $v$, apical part of vesica; ar.s, articular sclerite; $d$-l.l, dorso-lateral lobes of conjunctiva; ej.r, ejaculatory reservoir; l.l.v, left lobe of basal part of vesica; r.l.v, right lobe of basal part of vesica; $s . g p$, secondary gonopore. Scale bar: $0.14 \mathrm{~mm}$. 
and concave membranous inner walls. Similar, but much smaller lobe lying at left wall of basal part of vesica near its base. At dorsal wall of basal part of vesica near place where endosomal wall adhering to anterior margin of ejaculatory reservoir, apical part of vesica originating. It looking like narrow, long tube straight or curved to the left at base and twisted spirally in remaining part. For most of its length, this tube possesses a membranous wall closely adjoining the strongly sclerotised wall of ductus ejaculatorius located inside; only the outer portion of membranous wall capable of swelling. Secondary gonopore lying at apical part of vesica terminally. In Rh. parumpunctatus, spiral part forming one small and one significantly larger turn oriented clockwise in rest and lying anticlockwise in completely inflated aedeagus (see the section 'Functional morphology of the genitalia' below); remaining distal section curving slightly outward, straight behind bend and curved slightly ventrally before extreme apex; secondary gonopore small (Figs 2-6). In C. hyoscyami, spiral part with two small and one significantly larger turn, oriented clockwise, at rest and when in completely inflated condition of aedeagus; secondary gonopore large, due to spoon-like expanding walls of vesica (Figs 7-9).

Terminalia of females (Figs 10-12), as in all rhopalids, drawn into abdomen and covered by ventrite VII. Gonocoxites VIII, being the largest genital plates, transverse, with slightly elongated and rounded posterior-inner angle and more elongated, pointed and curved dorsally anteriorinner angle; inner margin between them convex. Gonapophyses I slightly shorter than the latter; their inner parts, located between gonocoxites VIII and visible from outside, longitudinally oval, convex and sclerotised, attached by anterior end to anterior inner angle of gonocoxites VIII; located under gonocoxites VIII, their outer parts and apices lamellar; apices directed posteriad, pointed and sclerotised. Inner margins of gonapophyses I connected to each other by wide membrane reinforced in middle by large sclerotised incomplete ring opened at dorsal side; parts of membrane on sides of incomplete ring long, forming a deep fold, concave in the dorsal direction. Dorsal wall of each gonopophysis I along its outer margin reinforced with narrow thin sclerotised band, anterior end of which arcuate curved and fused with lamellar process of laterotergite IX (part of gonangulum), and posterior end significantly short of reaching apex of gonapophysis.

Laterotergites IX rather large, transverse, close to rhomboid in shape; their inner angle short, wide and rounded; outer angle long, strongly elongated and directed laterally and anteriad. Outeranterior margin of each laterotergite thickened at dorsal side; anterior angle continuing anteriad as sclerotised, dorso-ventrally flattened process almost reaching under gonocoxites VIII to its concave anterior margin. Outer angle, thickening of outer-anterior margin, and lamellar process of each laterotergite IX together entering into composition of gonangulum. Outer-posterior margins of laterotergites IX fused with margins of rather long tergite of corresponding segment. Laterotergites VIII rather small, transverse, with widely rounded internal angle, overlying outer parts of laterotergites VIII and bearing spiracles; their outer margins connecting to margins of tergite VIII without suture in anterior part.

Reduced gonocoxite IX lying along anteriorinner margin of laterotergite IX and having the appearance of a rod-shaped sclerite slightly widened in middle of length; reaching apex of lamellar process of laterotergite IX and lying dorsally to it. Gonocoxite IX rigidly connecting with anterior margin of laterotergite IX and its lamellar process, but not completely fused with them. Gonapophyses II as longitudinal, rather wide membranous swellings located diagonally under gonapophyses I, their posterior ends converging and contiguous, and anterior ends widely diverging. Posterior ends of gonapophyses II forming small convex sclerites visible from outside at rest. Middle of each gonopophysis II with thin sclerotised band, anterior end of which arcuately curving and is fused with anterior end of gonocoxite IX. Part of gonapophysis inside this band, membranous, lamellar, with convex margin; part outside band with form of weakly sclerotised plate curved dorsally and posteriad at anterior end, where it forms a sclerotised area on ventral wall of gynatrial sac; this area by its outer margin is fused with process of gonocoxite IX, and its inner margin forming a rather short and wide sclerotised band directed medially and posteriad. 
Proctiger as wide elliptical sclerotised tube somewhat flattened dorso-ventrally, with dorsal wall longer than ventral one, and sclerotised valve inside with lips-shaped flaps. All visible from outside parts of terminalia covered with dense, rather long setae.

Gynatrial sac large (Figs 11, 12). Its posterior part posteriorly resembling a wide and rather long semicircular fold with a convex dorsal wall and a flat ventral one. Transverse ring sclerites lying on ventral wall of this fold with thin edging; relatively small in Rh.parumpunctatus (Fig. 11) and relatively larger in C. hyoscyami (Fig. 12). Anterior to this fold, between anterior ends of laterotergites IX, gynatrial sac widening and forming a pair of lateral pouches with convex dorsal walls; ventrally these pouches reinforced with bends of weakly sclerotised lamellar parts of gonapophyses II, described above.

Anterior part of gynatrial sac wide, its anterior angles sharply elongated, set apart, rather short and wide in Rh.parumpunctatus (Fig. 11) and narrow, long and having connivent bases in C. hyoscyami (Fig. 11). Gynatrial cone lying closer to base of common oviduct, large and consisting of two parts. Its basal part lying in inclined position, more or less close to transverse plane, subconical in shape, flattened dorso-ventrally, with broad base and directed to the right apex. Anterior wall of basal part of cone as triangular protrusion continuing anteriad and reaching base of common oviduct. In Rh. parumpunctatus, dorsal wall of basal part of gynatrial cone at some distance from its base with broad and deep semicircular fold (Fig. 11); basal part of cone in C. hyoscyami without such a fold, but with triangular prominence at left side and furthermore with shallow fold on anterior-right wall. Internal surface of dorsal wall of basal part of cone bearing narrow, arcuately curved groove with thickened margins forming shallow folds; one end of this groove reaching mouth of common oviduct, and other end going into apical part of gynatrial cone. In Rh. parumpunctatus, radius of curvature and relative length of this groove larger than in C. hyoscyami. Apical part of gynatrial cone tubular and extending from apex of basal part. In $R h$. parumpunctatus, proximal half of this part rather narrow and continuing the curvature of groove on dorsal wall of basal part of cone; distal half wider, also arcuately curved, but located in longitudinal plane almost perpendicular to longitudinal plane of proximal half and ventrally to transverse plane of the latter (Fig. 11). In C. hyoscyami, apical part of gynatrial cone with appearance of simple, short, rather wide tube (Fig. 12).

Slightly sclerotised spermathecal duct attached terminally to apical part of gynatrial cone, uniformly wide and very long, forming 5-6 turns of small radius basally and of larger radius distally, with part of turns oriented clockwise and part against. Distal turns of duct embracing base of large, slightly sclerotised spermathecal capsule, with ellipsoid shape.

\section{Functional morphology of the genitalia}

The functioning of the genitalia in their mutual contact can only be described speculatively, since it is almost impossible to observe their contact directly in living insects. Thus, the processes occurring inside the body of a living female are reconstructed by comparing the structure and functioning of the aedeagus with the structure of the internal genitalia of the female.

Rhopalus parumpunctatus. At rest, the conjunctiva and vesica are drawn into the theca (Fig. 2); only the apices of dorsal-lateral lobes and a small portion of the big turn and apex of the distal part of vesica protrude inside. After penetration of the aedeagus into the gynatrium, the conjunctiva begins to swell and pushes the vesica outside. Then the dorso-lateral lobes of conjunctiva emerge, swell slightly and unfold about 140 degrees, so that their apices turn out to be directed laterally and anteriad (Fig. 3). At the same time, they enter the lateral pouches of the posterior part of gynatrial sac, hooking by their sclerotised tubercles and protruding ventral margins of sclerites to the anterior margin of the ventral wall of posterior part of the gynatrial sac and simultaneously their swelling membranous parts function as transversal struts. The apex of the apical part of the vesica enters the basal part of the gynatrial cone and sets against its anterior wall. The apex of the right (large) sclerotised lobe of the basal part of the vesica is still directed posteriad and is stuck into the fold of the dorsal wall of the basal part of gynatrial cone. Further swelling of the aedeagus leads to the release of 




Figs 10, 11. Female terminalia in Rhopalus parumpunctatus. 10, external terminalia, ventral view; 11, internal ectodermal genitalia, dorsal view. b.g.c, basal part of gynatrial cone; a.g.c, apical part of gynatrial cone; gon, gonangulum; gp.I, gonapophysis I; f.d.w, fold on dorsal wall of basal part of gynatrial cone; gp.II, gonapophysis II; gx.VIII, gonocoxite VIII; gx.IX, gonocoxite IX; l.p.g, lateral pouches of gynatrial sac; lt.VIII, laterotergite VIII; It.IX, laterotergite IX; prg, proctiger; sp.d, spermathecal duct. At fig. 10, the genital plates are shown somewhat driven apart and the inner margins of laterotergites IX are shown slightly turned ventrally; at fig. 11, the basal part of gynatrial cone is shown in more or less dorso-ventral plane. Scale bar: $0.14 \mathrm{~mm}$. 


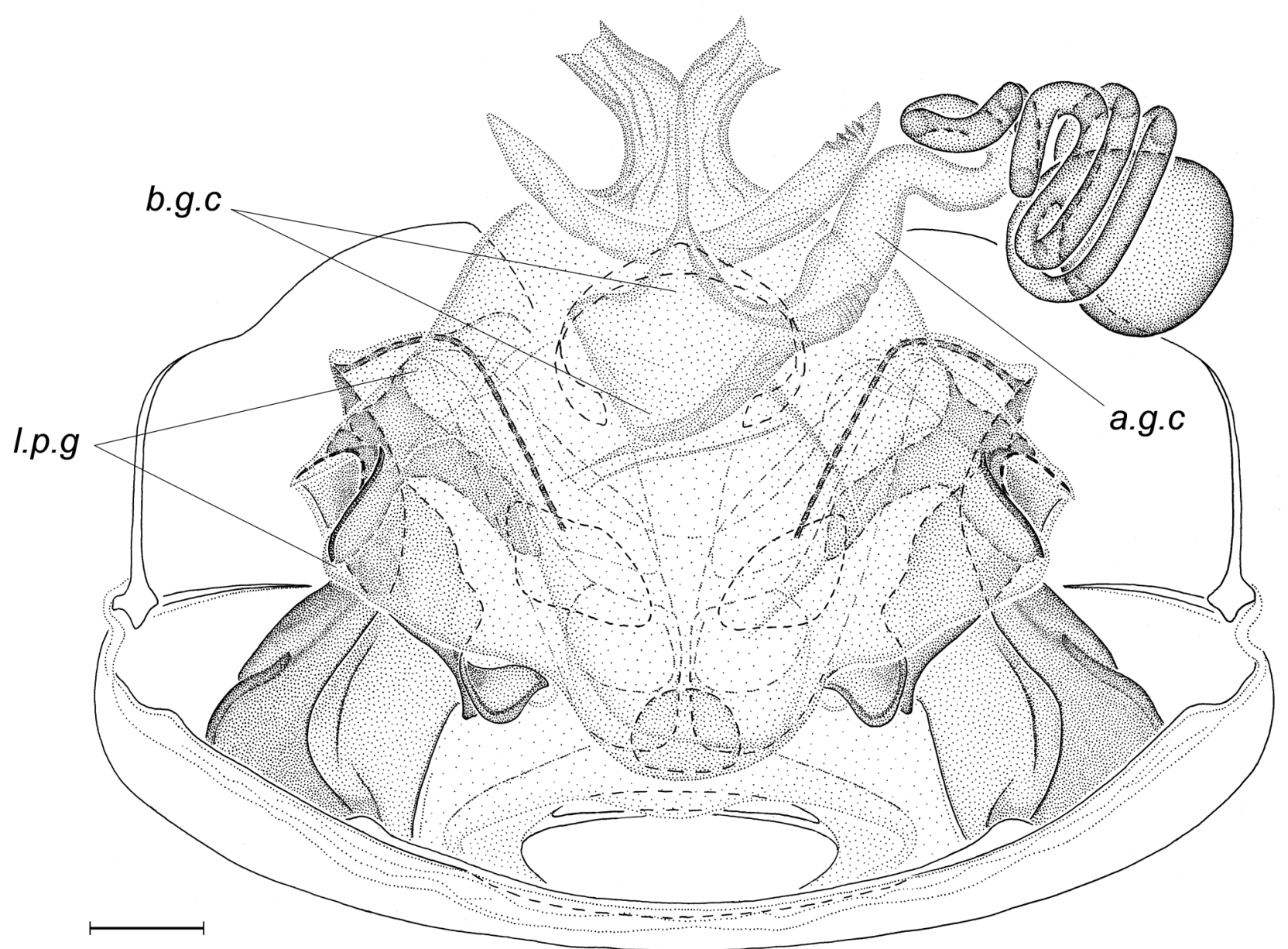

Fig. 12. Female internal ectodermal genitalia in Corizus hyoscyami. b.g.c, basal part of gynatrial cone; a.g.c, apical part of gynatrial cone; l.p.g, lateral pouches of gynatrial sac. The basal part of gynatrial cone is shown in more or less dorso-ventral plane. Scale bar: $0.14 \mathrm{~mm}$.

the basal part of the conjunctiva from the theca and complete swelling of the dorso-lateral lobes which become firmly fixed in the lateral pouches, and to swelling of the membranous parts of the vesica, which are already completely extruded from the conjunctiva (Fig. 4). Due to swelling of the basal part of vesica, its right (large) lobe bends to the left, then moves to the left side and bends by its apex anteriorly and to the right, describing a semicircle (Fig. 5). At the same time, the lobe entrains the dorsal wall of the basal part of gynatrial cone (in the fold of which it is placed) and presses it to the wall of the left (small) lobe of the basal part of vesica. The distal part of vesica, which at the beginning of the erection of the aedeagus was located in the dorso-ventral plane so that its turns were oriented clockwise, rotating approximately 140 degrees under the action of the right lobe, and the turns became oriented anticlockwise. At the same time, the apex of distal part of vesica is pushed into the narrow apical part of the gynatrial cone due to the tension of the dorsal wall of the basal part of the latter under the action of the right lobe of the vesica. Herewith the bend at the apex of the apical part of vesica at first corresponds to the bend of the channel in base of the apical part of gynatrial cone, and after the flip-over, this vesical bend corresponds to the bend in the distal part of the channel; i.e., the apex of vesica screws into the apical part of the gynatrial cone like a corkscrew. In the end, the apex of the apical part of the vesica is found to be directed to the right and entrains the apical part of gynatrial cone, which is filled entirely by the 
vesical apex. Probably, the presence of turns in the spermathecal duct is connected with this: these turns have the function of a spring, straightening when the apical part of the gynatrial cone moves. The function of the groove on the dorsal wall of the basal part of gynatrial cone remains unclear; either it serves to direct the extreme apex of vesica into the channel of distal part of the cone, or it performs the function of the duct through which the spermatozoa migrate from the spermatheca to the common oviduct to fertilise the eggs there.

The main stages of swelling of the aedeagus in Corizus hyoscyami are the same as those in $R h$. parumpunctatus. The differences are that, due to the less developed membranous portion of the basal part of the vesica, its right lobe bends less strongly to the right. Apparently, this lobe does not hook onto the wall of the basal part of the gynatrial cone, since there is no fold in the corresponding part of the wall, in contrast to $R h$. parumpunctatus; the right wall of the basal part of the cone forms a triangular protrusion, in which, apparently, a relatively small membranous portion of the vesica takes a place. The right lobe of the vesica constantly tightly fits the wall of the distal part of the vesica posteriorly, guides it and promotes its movement around the circumference. The apex of the left lobe, on the contrary, goes into the fold of the anterior right wall of the basal part of gynatrial cone, pulls it up and presses it to the anterior wall of the distal part of vesica in the place where the right lobe is adjacent to it. Thus, the distal part of vesica does not turn over, but describes an almost complete circle in almost the same plane but only somewhat inclined to the left side. At the beginning of the aedeagus erection, the extreme apex of the vesica is directed to the left and enters the wide opening of the apical part of gynatrial cone; at the point of complete inflation of the aedeagus, the apex of the vesica is directed posteriad, and the apical part of gynatrial cone is bent correspondingly.

\section{Congruence and possibility of structural isolation}

Preliminary reasoning. Mayr (1963), in his classification of the mechanisms of reproductive isolation, divided them into two groups: pre- mating and post-mating mechanisms, and attributed structural or mechanical isolation to the first group. In my opinion, a more rigorous approach would be to consider a separate group of copulation mechanisms, which includes structural and sensory isolation; the latter in the sense of De Wilde (1964) and Eberhard (1985) is hardly discussed in this work.

Often, the presence or absence of the function of structural isolation in genitalia are judged by the degree of their morphological differences between species, and only parts of the genitalia, visible from the outside and usually not coming into direct contact as congruent structures, are considered. Such structures in the true bugs and many other insects are the endosome (or endophallus) which is indrawn into the theca at rest, and the gynatrial sac (or bursa copulatrix, also sometimes called the vagina). In essence, these are the "key" and "lock". In general, the structures of the terminalia in insects, involved in copulation, can be divided into three groups according to their functions: 1) auxiliary structures involved in the initial contact, performing a sensory function and serving to prepare the genitalia for contact (parameres, phallobase and theca in heteropteran males; genital plates, gonapophyses, triangulum and other parts of the vestibulum in females); 2) structures that serve to the mutual fixation of the genitalia during copulation (membranous and sclerotised lobes of the conjunctiva and vesica, spicules, denticles, spine fields, etc. in males; pouches and folds of the gynatrial sac in females); and 3) structures directly providing the transmission of seminal fluid or spermatophores from male to female (the apex of vesica in males; the gynatrial cone in females). The auxiliary structures of one sex do not necessarily have to be congruent in their morphology to those of the opposite sex within the same species. However, the structures that serve to anchor of the genitalia and transfer seminal fluid must have a high degree of congruence so that these functions are performed successfully. Of course, these structures can also have a sensory function and implement the socalled sensory reproductive isolation.

It is not enough to simply state the differences in the morphology of these structures in order to judge whether they have the function of structural 
isolation, since, using the terminology of the lock-and-key metaphor, sometimes one key can open several different locks and one lock can be opened with several different keys. It is necessary to compare the structure of those organs from the second and third groups listed above, which may come into direct contact during interspecific mating. In addition, not only morphological, but also functional congruence should be considered, since similar structures of the genitalia can function differently, and different structures can produce the same functional effect. Obviously, the function of structural isolation is carried out only when at least one of the following conditions is fulfilled: 1) the genitalia of opposite sexes are so different that copulation cannot begin: the aedeagus (or penis) cannot be inserted into the female genital opening (as, for example, in insects having a paired penis: even a small change in the angle between the copulatory appendages of males or the distance between the genital opening of females makes penetration impossible); 2) the aedeagus is inserted into the female genital tract, but cannot be fixed there because the soft and swelling part of the aedeagus cannot completely unfold or because its parts do not correspond to parts of the gynatrium; 3) the aedeagus swells and becomes fixed in the gynatrium, but its structures damage the gynatrium and this leads to the impossibility of a normal egg-laying or to the death of the female; 4) the aedeagus during the process of unfolding and swelling inside the female genitalia is damaged, and this makes its further functioning impossible; 5) the aedeagus is normally swelled and fixed in the gynatrium, but the structures that perform the function of direct transfer of seminal fluid do not come into proper contact, and as a result this function is not performed; and 6) copulation cannot be completed because the aedeagus is stuck in the female genitalia, and the male cannot withdraw it. In most cases, it is almost impossible to directly observe the contact of congruent parts of the genitalia that takes place inside the body of female, and any intervention leads to disruption or termination of this process. This is determined by the fact that the aedeagus is in a state of erection under the pressure of an erection fluid, and this pressure can be changed rapidly; in addition, the rapid retraction of the endosome into the theca is due to the elastic hyaline bands which are strongly strained in the erect aedeagus. Many insects are adapted to interrupt copulation very quickly in cases of danger. The exceptions are groups with strongly sclerotised structures in the genitalia of both sexes, which take time to disengage.

Therefore, it is often possible to judge the presence of the structural isolation between different species only indirectly by comparing the structure of gynatrium and the completely inflated aedeagus, finding the correspondence of these structures within the same species and comparing them for different species. An examination of completely inflated aedeagi is made possible by the method of their hydraulic inflation proposed by the author (Gapon, 2001); this method makes it possible to change the pressure of water entering through a glass microcapillary into an aedeagus, creating the negative pressure and thus tracing the successive stages of unfolding and swelling of an endosome, movement of its lobes, spicules, vesica and other structures.

Testing the possibility of structural reproductive isolation in the species examined. In a case of the intergeneric mating, the subject of this article, the biotopical and seasonal premating modes of reproductive isolation (according to the classification of Mayr (1963)) are not realised, since both species are sympatric and rather similar in their ecological characteristics. According to Puchkov (1986), adult individuals of Corizus hyoscyami hibernate among various plant residues along edges of fields, roadsides, on fallow lands, at forest edges, in forest belts, parks, on ravine slopes and river terraces; in the conditions of the foreststeppe of Ukraine, they migrate from wintering places to new biotopes in early May, where they feed on species of Matricaria, Arctium, Sonchus, Linaria, Silene, Taraxacum, Euphorbia and many others. And from mid-May, bugs accumulate on Hyoscyamus niger, Ononis spinosa and Erodium spp. Rhopalus parumpunctatus also inhabits various mesophilous and moderately xerophilous biotopes: glades and forest edges, thickets of ruderal-grass vegetation near roadsides, along ditches, forest belts, on slopes of ravines and river terraces and other similar places. The trophic links of this species are extremely extensive and include plants of the families Caryophyllaceae, Lamiaceae, 
Brassicaceae, Asteraceae, and others. Females of both species in the forest-steppe zone lay eggs in the second half of May. It is worth noting that in Great Britain, according to Max Barclay (pers. comm.), the two species occur in different habitats and in general association with different plant genera, and C. hyoscyami has recently hugely expanded its distributional range, going from rare and local to quite common and widespread in only the last 10-15 years. However, according to my observations, both species are common and found in the same biotopes in different regions of the European part of Russia. Since they are not separated in space and time on a significant part of the common range, they must have some other isolating mechanisms.

Obviously, in the instance considered the premating ethological isolation mechanism also did not operate and in one way or another neither did the mechanism of structural isolation. Since mating began and lasted for a rather long time, the genitalia of the male and female would appear to be rather congruent for this. It is also obvious that this mating could not lead to intergeneric hybrids, since no hybrids of the taxa under consideration have been found in nature. So, in this case either one of the post-mating isolation mechanisms was activated or, nevertheless, the mechanism of structural isolation partially worked: the aedeagus was able to penetrate and fix itself in the gynatrium, but the genitalia may not have been sufficiently congruent for insemination. Consideration of the post-mating isolation mechanisms is beyond the scope of this work and there are no data to judge the possibilities of such isolation, except for information on the chromosome complement, which includes the same number of autosomes, microchromosomes and sex chromosomes in both species: 5A + m + X0 (Ueshima, 1970).

The photographs show that the copulating pair consists of the male of Corizus hyoscyami and the female of Rhopalus parumpunctatus. However, in addition to this registered combination, I will consider the opposite variant of reciprocal mating.

The first thing that attracts attention is the somewhat larger genitalia of the male and female of $C$. hyoscyami, which has a larger body size. Therefore, the possibility of injury to the gynatrium of $R h$. parumpunctatus by the completely swelled aedeagus of $C$. hyoscyami in the corresponding cross cannot be excluded. However, it is very difficult to assess the possibilities of stretching the walls of the gynatrium in living insects. Several photographs show that the female abuts with its hind legs against the abdomen of the male (Figs 13-16 as electronic supplementary material), apparently trying to interrupt the copulation, which may indicate its discomfort, possibly caused by injuries to the gynatrium. This does not support the hypothesis of sensory isolation: the male does not interrupt copulation with the female of another species, and the female cannot interrupt the process. In any case, traumatically or not, the function of anchoring the aedeagus was carried out. And, judging by the very similar structure of the dorso-lateral lobes of the conjunctiva and the lateral pouches of the gynatrial sacs in the both species, this function is performed identically in them, but the same cannot be said of the function of the structures that realise the transfer of seminal fluid. The complicated implementation of this function is characteristic for both species, and in Rh.parumpunctatus it is more complicated than in C. hyoscyami.

In mating of the male of $C$. hyoscyami and female of $R h$. parumpunctatus, the incongruence of the apical part of the vesica and the apical part of the gynatrial cone may have the following consequences. Because of the wide secondary gonopore, the vesica is not able to penetrate through the narrow opening of the apical part of the gynatrial cone. In addition, it is obvious that in order to overcome the bend of the apical part of gynatrial cone, the vesica must have a corresponding bend before its apex and carry out the flip-over taking place in Rh. parumpunctatus. As a result, the inability of the vesica to normally penetrate into the channel of the distal part of gynatrial cone should lead to perforation of the channel wall or injury to the vesical apex (taking into account that the aedeagus is larger than the gynatrium), or at least to plugging of the secondary gonopore because it abuts against the wall of the gynatrial cone in the place of its bend.

In the hypothetical case of the mating of a male $R h$. parumpunctatus with a female $C$. hyoscyami, it seems that nothing prevents the apical part of vesica from penetrating into the apical part 
of gynatrial cone, having a wide lumen of the channel, and making the flip-over in it. However, the right lobe of the basal part of vesica in this case will not be able to cling to the fold on the wall of the basal part of gynatrial cone (since this fold is absent in C. hyoscyami) and will not entrain this wall. As a result, the long apical portion of the apical part of vesica cannot enter the apical part of gynatrial cone but having turned over it will be directed to the right inside the basal part of the cone. This cannot completely exclude the possibility of sperm penetration into the spermatheca because, as Pluot (1970) showed for the genus Dysdercus Audinet-Serville, 1835, the spermatozoa can migrate from the part of the gynatrial cone, located close to the opening of the spermathecal duct, into the spermathecal capsule under the action of the secretion of its apical cells. However, in the case of such mating, the number of spermatozoa reaching the capsule would be small, taking into account the volume of the basal part of gynatrial cone in C. hyoscyami, and the fact that the cone is widely opened ventrally. Such migration is probably difficult for the spermatozoa, since for their migration from the spermathecal capsule to the common oviduct through the basal part of gynatrial cone serves the special groove on its dorsal wall (at least, this is the most likely function of this groove). Thus, it is unlikely that insemination will succeed.

As a result of the purely speculative comparison of the structure and functioning of the male and female genitalia in the two species considered, it can be concluded that the genital structures of both species, which serve for anchoring, are completely congruent to each other in both variants of interspecific crosses (although corresponding parts of the aedeagi somewhat differ in the examined species), and if their contact does not result in injury to a female of $R h$. parumpunctatus when mating with a male of C. hyoscyami, then these organs do not have the function of structural isolation. The situation with the structures that serve for the transfer of seminal fluid is different; in both species, these structures have different morphology and functioning. The proposed schemes of the functioning of these structures indicate their not only morphological, but also functional incongruence in interspecific crosses in both combinations, and, as a result, the impossibility of normal insemination. It is difficult to say whether the described mechanisms are actually realised in the considered species, but at least they are possible.

\section{Addenda}

Electronic supplementary material. Image files: Fig. 13, Fig. 14, Fig. 15, and Fig. 16. File format: JPEG. Available from: https://www.zin.ru/journals/zsr/publication.asp?id=1319

Explanation note. Additional photographs of mating Corizus hyoscyami (male) and Rhopalus parumpunctatus (female), Novgorod Province. Photographs by E.Yu. Kirtsideli.

\section{Acknowledgements}

I heartily thank Evgeniy Yu. Kirtsideli and Maria A. Berlina (St Petersburg) for providing the photographs that underpin this work. I am also very grateful to Max Barclay (Natural History Museum, London) for the linguistic correction of the text and valuable comments. The work was performed in the frameworks of the state research project No. AAAA-A19-119020690101-6 and supported by the Presidium RAS program No. 41 "Biodiversity of natural systems and biological sources of Russia".

\section{References}

Dufour L. 1844. Anatomie générale des diptères. Annales des Sciences Naturelles. Troisième série. Zoologie, 1: 244-264.

Eberhard W.G. 1985. Sexual selection and animal genitalia. Cambridge: Harvard University Press. $244 \mathrm{p}$.

Gapon D.A. 2001. Inflation of Heteropteran aedeagi using microcapillaries (Heteroptera, Pentatomidae). Zoosystematica Rossica, (2000), 9(1): 157160.

Gapon D.A. 2007. Structure, function, and morphological conformity of the male and female genitalia in the true bug genus Pyrrhocoris Fall. (Heteroptera, Pyrrhocoridae). Entomologicheskoe Obozrenie, 86(4): 729-741. (In Russian. English translation: Entomological Review, 2007, 87(9): 1099-1108. https://doi.org/10.1134/S0013873807090011)

Konstantinov F.V. \& Gapon D.A. 2005. On the structure of the aedeagus in shield bugs (Heteroptera, Pentatomidae): 1. Subfamilies Discocephalinae and 
Phyllocephalinae. Entomologicheskoe Obozrenie, 86(2): 334-352. (In Russian. English translation: Entomological Review, 2005, 85(3): 221-235).

Masly J.P. 2012. 170 years of "lock-and-key": genital morphology and reproductive isolation. International Journal of Evolutionary Biology, 2012: 1-10. https://doi.org/10.1155/2012/247352

Mayr E. 1963. Animal Species and Evolution. Cambridge: Belknap Press of Harvard University Press. 797 p.

Pluot D. 1970. La spermathèque et les voies genitals femelles des Pyrrhocoridés (Hemiptera). Annales de la Société entomologique de France, 6(4): 777-807.

Putshkov V.G. 1986. Poluzhestkokrylye semeystva Rhopalidae (Heteroptera) fauny SSSR [Bugs of the family Rhopalidae (Heteroptera) of the fauna of the USSR]. Opredeliteli po Faune SSSR, 146. Lenin- grad: Nauka. 132 p. (In Russian).

Shapiro A.M. \& Porter A.H. 1989. The lock-and-key hypothesis: evolutionary and biosystematic interpretation of insect genitalia. Annual Review of Entomology, 34: 231-245. https://doi.org/10.1146/ annurev.en.34.010189.001311

Štys P. 1961. Morphology of the abdomen and female ectodermal genitalia of the Trichophorous Heteroptera and bearing on their classification. In: Strouhal H. \& Beier M. (Eds). XI. Internationaler Kongress für Entomologie, Wien, 17. bis 25: verhandlungen, 1: 37-43. Wien : Organisationskomittee des XI. Internationalen Kongresses für Entomologie.

Ueshima N. 1979. Hemiptera II: Heteroptera. In: John B. (Ed.). Animal cytogenetics, 3(6). Berlin \& Stuttgart: Gebrüder Borntraeger. 113 p.

Received 30 November 2018 / Accepted 24 December 2018. Scientific editor: I.A. Gavrilov-Zimin 